\title{
Alterações Citogenético-Moleculares no Gene F0X01 em uma Criança com Rabdomiossarcoma Alveolar: Relato de Caso
}

doi: https://doi.org/10.32635/2176-9745.RBC.2018v64n3.51

Citogenetic-Molecular Alterations in FOX01 Gene in a Child with Alveolar Rhabdomyosarcoma: Case Report
Cambios Citogenetico-Moleculares en el Gene FOX01 en un Niño con Rabdomiossarcoma Alveolar: Relato de Caso

Nicolas Cabral Cunha'; Arissa Ikeda Suzuki²; Fernanda Ferreira da Silva Lima³; Priscila Valverde Fernandez ${ }^{4}$; Paulo Antônio Silvestre de Faria ${ }^{5}$; Teresa de Souza Fernandez ${ }^{6}$; Sima Esther Ferman ${ }^{7}$

\section{Resumo}

Introduçáo: O rabdomiossarcoma (RMS) é o tumor de tecidos moles mais comum da infância. Pode ser classificado em dois subtipos principais: o rabdomiossarcoma alveolar (RMSa) e o embrionário (RMSe). No RMSa, o prognóstico é desfavorável quando comparado ao RMSe, necessitando de tratamento intensificado; dessa forma, a distinção entre ambos os subtipos é fundamental. Citogeneticamente, o RMSa apresenta translocaçôes cromossômicas envolvendo o gene FOXO1 em 80\% dos casos. A metodologia de hibridização in situ por fluorescência (FISH) tem sido muito utilizada para caracterizar o RMSa. Relato do caso: Paciente do sexo feminino, com 7 anos de idade, apresentou ao diagnóstico RMSa parameníngeo, sem metástase ao diagnóstico. A análise por meio de FISH mostrou a translocação envolvendo o gene FOXO1 e uma cópia extra desse gene. A paciente foi incluída no protocolo de tratamento do EpSSG, classificada como grupo de alto risco e recebeu quimioterapia e radioterapia. No final do tratamento, foi observada resposta parcial e iniciada quimioterapia de segunda linha. Não houve resposta clinicorradiológica e a paciente evoluiu com progressão de doença local refratária ao tratamento e óbito após um ano do diagnóstico. Conclusão: De acordo com o nosso conhecimento, é a primeira descrição de um caso de RMSa apresentando a translocação do gene $F O X O 1$ e uma cópia extra desse gene em clones separados. Sáo necessários ainda novos estudos, a fim de compreender melhor o significado prognóstico da presença dessas alteraçóes.

Palavras-chave: Rabdomiossarcoma; Criança; Translocação Genética; Hibridização in situ Fluorescente; Proteína Forkhead Box O1.

\section{Abstract}

Introduction: Rhabdomyosarcoma (RMS) is the most common soft tissue tumor of childhood. It can be classified into two main subtypes: alveolar rhabdomyosarcoma (aRMS) and embryonal (eRMS). In aRMS the prognosis is unfavorable when compared to eRMS, requiring intensified treatment, thus the distinction between both subtypes is fundamental. Cytogenetically, aRMS present chromosomal translocations involving the FOXO1 gene in $80 \%$ of the cases. The fluorescence in situ hybridization methodology (FISH) has been widely used to characterize aRMS subtype. Case Report: A 7-year-old female patient presented with parameningeal aRMS, non-metastatic at diagnosis. FISH analysis showed translocation involving the FOXO1 gene and an extra copy of this gene. The patient was enrolled in the EpSSG treatment protocol, classified as a high-risk group and received chemotherapy and radiotherapy. At the end of treatment a partial response was observed, and second line chemotherapy was started. There was no clinical-radiological response and the patient progressed with local disease, refractory to rescue treatment and died of disease one year after diagnosis. Conclusion: To our knowledge, this is the first case of aRMS presenting $\mathrm{FOXO1}$ gene translocation and an extra copy of this gene in separate clones. More studies are necessary to understand the prognostic significance of these alterations.

Key words: Rhabdomyosarcoma; Child; Translocation, Genetic; In Situ Hybridization, Fluorescence; Forkhead Box Protein O1.

\section{Resumen}

Introducción: El rabdomiosarcoma (RMS) es el tumor de tejidos blandos más común de la infancia. El RMS puede clasificarse en dos subtipos principales, el rabdomiosarcoma alveolar (RMSa) y el embrionario (RMSe). El RMSa presenta un pronóstico desfavorable si se compara al RMSe, habiendo así necesidad de intensificación del tratamiento. De esta forma, la distinción entre RMSa y RMSe es fundamental. Citogéticamente, el RMSa presenta en cerca del $80 \%$ de los casos de translocación cromosómica que involucra el gen $F O X O 1$. La metodología de Hibridación fluorescente in situ (FISH) ha sido muy utilizada para caracterizar el RMSa. Caso de estudio: Paciente del sexo femenino, de 7 años de edad presentada con un diagnóstico de RMSa parameningeo, sin metástasis. El análisis a través del FISH mostró la translocación envolviendo el gen FOXO1 y una copia extra de este gen. La paciente fue incluida en el protocolo de tratamiento del EpSSG, clasificado como grupo de alto riesgo y recibió quimioterapia y radioterapia. Al final del tratamiento fue observada una respuesta parcial y se inició la quimioterapia de segunda línea. No hubo respuesta clínicoradiológica y la paciente evolucionó con progresión de enfermedad local, refractaria y óbito después de 1 año del diagnóstico. Conclusión: De acuerdo con nuestro conocimiento, este es el primer caso de un niño con RMSa presentando la translocación del gen FOXO1 y una copia extra de este gen en clones separados. Se necesitan nuevos estudios para comprender mejor el significado pronóstico de la presencia de estos cambios. Palabras clave: Rabdomiosarcoma; Niño; Translocación Genética; Hibridación Fluorescente in Situ; Proteína Forkhead Box O1.

\footnotetext{
${ }^{1}$ Instituto Nacional de Câncer José Alencar Gomes da Silva (INCA). Rio de Janeiro (RJ), Brasil. Orcid iD: https://orcid.org/ 0000-0001-7401-3670

${ }^{2}$ INCA. Rio de Janeiro (RJ), Brasil. Orcid iD: https://orcid.org/ 0000-0001-9689-5985

${ }^{3}$ INCA. Rio de Janeiro (RJ), Brasil. Orcid iD: https://orcid.org/ 0000-0002-6658-3101

${ }^{4}$ INCA. Rio de Janeiro (RJ), Brasil. Orcid iD: https://orcid.org/ 0000-0002-0196-4755

${ }^{5}$ INCA. Rio de Janeiro (RJ), Brasil. Orcid iD: https://orcid.org/ 0000-0003-1817-4888

${ }^{6}$ INCA. Rio de Janeiro (RJ), Brasil. Orcid iD: https://orcid.org/ 0000-0003-1299-4666

${ }^{7}$ INCA. Rio de Janeiro (RJ), Brasil. Orcid iD: https://orcid.org/0000-0002-7076-6779

Endereço para correspondência: Sima Esther Ferman. Praça Cruz Vermelha, 23 - $5^{\circ}$ andar. Serviço de Oncologia Pediátrica do INCA. Rio de Janeiro (RJ), Brasil. CEP 20230-130. E-mail: sferman@uol.com.br.
} 


\section{INTRODUÇÃO}

O rabdomiossarcoma (RMS) é o tumor de tecidos moles mais comum da infância e muito raro em adultos, com 4,7 novos casos/1 milhão de pessoas/ ano nos Estados Unidos (EUA) ${ }^{1,2}$. Aproximadamente $25 \%$ das crianças apresentam doença metastática ao diagnóstico, e os principais locais de acometimento são pulmôes, medula óssea, ossos e linfonodos. Em pacientes pediátricos, o RMS pode ser classificado em dois subtipos principais, o rabdomiossarcoma alveolar (RMSa) e o embrionário (RMSe), constituindo $20 \%$ e $80 \%$ dos casos, respectivamente ${ }^{3}$. O RMSa e o RMSe apresentam manifestaçôes clínicas e biológicas distintas. O RMSa ocorre principalmente em crianças mais velhas e está associado com mau prognóstico. A distinção entre RMSa e RMSe é de extrema importância, já que o RMSa apresenta maior incidência de metástases e um prognóstico desfavorável se comparado ao RMSe, havendo assim necessidade de uma diferenciação no tratamento ${ }^{4}$. O correto diagnóstico do RMS pode representar um desafio na rotina histopatológica ${ }^{5}$.

Citogeneticamente, o RMSa apresenta, em cerca de 80\% dos casos, translocaçôes cromossômicas envolvendo o gene FOXO1, sendo a t $(2 ; 13)(\mathrm{q} 35 ; \mathrm{q} 14)$ em $60 \%$ dos pacientes e at $(1 ; 13)$ (p36;q14) em 20\% $0^{6,7}$. Essas translocaçôes resultam na formação e aumento de expressão dos genes quiméricos PAX3-FOXO1 (FOXO1 também conhecido como FKHR) e PAX7-FOXO1, respectivamente. As proteínas de fusão são fatores de transcrição e determinantes da tumorigênese, sendo um preditor de pior prognóstico ${ }^{5}$. Dessa forma, a hibridização in situ por fluorescência (FISH) tem sido muito utilizada para a pesquisa do rearranjo envolvendo o gene FOXO1, como um biomarcador em RMS, caracterizando o subtipo alveolar da doença ${ }^{8}$. O objetivo deste estudo é relatar um paciente pediátrico que apresentou pelo FISH células com o rearranjo e células com uma cópia extra envolvendo o gene FOXO1, com o diagnóstico de RMSa e sua evolução clínica.

\section{RELATO DO CASO}

Paciente do sexo feminino, com 7 anos de idade, apresentou queixa de obstruçáo nasal progressiva, tendo tido o diagnóstico de amigdalite e iniciado antibioticoterapia. Na tomografia computadorizada (TC) de face, foi evidenciada massa com densidade de partes moles ocupando todo o seio esfenoidal, com destruição da parede anteroinferior, cavidades nasais e extensão para a rinofaringe. A paciente apresentou emagrecimento, apatia e pouca aceitação da dieta e evoluiu com oftalmoparesia e ptose palpebral à esquerda. A matrícula no Serviço de
Oncologia Pediátrica foi em 19/5/2005. Na ressonância nuclear magnética (RNM) de crânio e face, foi evidenciada formação expansiva infiltrativa, de contorno lobulado, predominantemente hipointenso na sequência em T1, com realce irregular por meio de contraste e restrição à difusão, com isocentro na cavidade nasal bilateralmente, envolvendo o septo nasal. A lesão se estendia lateralmente aos seios maxilares, notadamente à direita, superiormente às células etmoidais médias e posteriores, e posteriormente ao seio esfenoidal e rinofaringe, determinando obliteração completa do cavum (Figura 1A). Havia rechaço inferior do palato mole. A paciente foi submetida à rinoscopia com biópsia. A histopatologia revelou a presença de RMSa, definido como sítio primário de localização parameníngea, sem metástase ao diagnóstico (exame de líquor negativo). A análise imuno-histoquímica mostrou positividade citoplasmática para desmina e nuclear para miogenina em $90 \%$ das células, negatividade para pancitoqueratina, CD99 e NB84. A análise por meio da FISH, usando a sonda LSI FOXO1 (13q14) dual color, break apart rearrangement probe (Vysis, Abbott), segundo o Sistema Internacional de Nomenclatura de Citogenética Humana (ISCN) ${ }^{9}$, mostrou o seguinte resultado: nuc ish (FOXO1x2) (5'FOXO1 sep 3'FOXO1 x1)[132/200]/ nuc ish $(\mathrm{FOXO} 1 \times 3)[64 / 200] /$ nuc ish $(\mathrm{FOXO} 1 \times 2)$ [4/200]. Portanto, foi possível detectar por intermédio dessa metodologia dois clones anormais envolvendo o gene FOXO1. O primeiro apresentando, em 66\% do total de 200 células analisadas, a translocação envolvendo o gene FOXO1 e o segundo clone apresentando, em $32 \%$ do total de 200 células analisadas, uma cópia extra do gene FOXO1. Também foi observada, em $2 \%$ do total de 200 células analisadas, a presença de células normais. As alteraçóes citogenético-moleculares envolvendo o gene FOXO1 podem ser observadas na Figura 2.
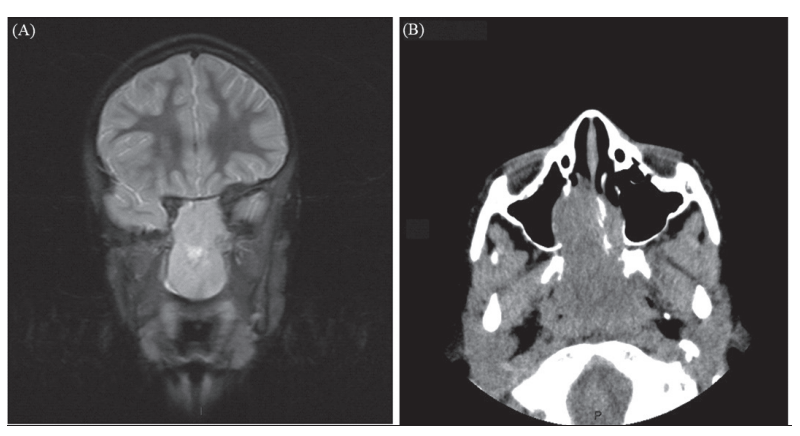

Figura 1. (A) Imagem de TC de crânio sem contraste evidenciando massa de partes moles ocupando todo o seio esfenoidal com destruição das paredes do seio com extensão para a rinofaringe; (B) Imagem de RNM de crânio AXI T2 apresentando volumosa formação expansiva e infiltrativa, ocupando o cavum e obliterando as coanas nasais, envolvendo o septo nasal na sua porção posterior, determinando espessamento mucoso e velamento parcial por secreção dos seios maxilares. A lesão rebaixa o palato fibroso e a base da língua. Há obliteração completa da coluna aérea da rinofaringe e parcial da orofaringe 

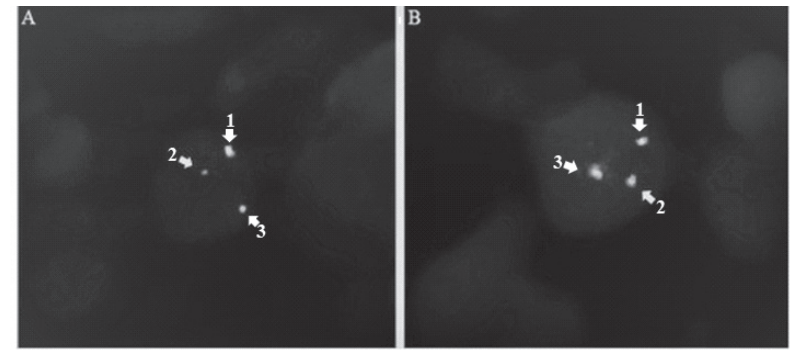

Figura 2. A análise de alterações citogenético-moleculares no gene FOXO1 em rabdomiossarcoma alveolar, mostrando em (A1) gene FOXO1, sinal de fusão normal do gene $\mathrm{FOXO1}$, mostrando que este alelo está intacto (ao microscópio esse sinal é representado pela cor amarela, ocorre a sobreposição dos sinais verde e vermelho do gene) e (A2) e (A3) dois sinais separados mostrando o rearranjo deste gene (ao microscópio são observados dois sinais verde e vermelho separados); (B1), (B2), e (B3) são observados três sinais de fusão do gene $\mathrm{FOXO1}$, sendo que um sinal representa uma cópia extra do gene (ao microscópio, esse sinal é representado pela cor amarela, ocorre a sobreposição dos sinais verde e vermelho do gene)

A paciente foi incluída no protocolo de tratamento do EpSSG como RMS náo metastático, classificado como grupo de alto risco, e recebeu quimioterapia com ifosfamida, actinomicina e vincristina, e radioterapia na dose 50,4 Gy como tratamento local. Apresentou resposta parcial, mas, como mantinha lesão residual no sítio primário (Figura 1B) ao término do tratamento, foi iniciada quimioterapia de segunda linha, com carboplatina, doxorrubicina e ciclofosfamida. Não houve resposta clinicorradiológica e a paciente evoluiu com progressáo de doença local, refratária ao tratamento e óbito após um ano do diagnóstico. Este estudo foi aprovado pelo Comitê de Ética em Pesquisa (CEP) do Instituto Nacional de Câncer José Alencar Gomes da Silva (INCA) sob o número 119/07.

\section{Pesquisa de alterações CItogenético-MOLECULARES nO GENE FOXO1 PELO MÉTODO DE FISH}

A técnica de FISH para pesquisa de alteraçôes citogenético-moleculares envolvendo o gene FOXO1 foi realizada utilizando a sonda LSI FOXO1 (13q14) dual color, break apart rearrangement probe (Vysis, Abbott) com o material em parafina, segundo as recomendaçóes do fabricante. As amostras de tecido foram seccionadas em 4 micrômetros e aderidas em lâminas polarizadas. Foi realizado o pré-tratamento do material, em seguida foi dimensionado $10 \mu \mathrm{l}$ da mistura-sonda previamente desnaturada na amostra e realizada a hibridização. Uma soluçấo de DAPI/Antiphade $(125 \mathrm{ng} / \mathrm{ml})$ foi aplicada sobre o tecido e a área foi coberta com uma lamínula de vidro. A análise foi realizada em microscópio de fluorescência (Olympus BX51) com filtros apropriados e o resultado obtido foi adquirido pelo Sistema de captura
ISIS MetaSystems, Zeiss. O valor do ponto de corte foi calculado por meio da função "beta inverso" (BETAINV) disponível no microsoft excel, capaz de determinar falsos positivos ${ }^{10}$. Utilizaram-se três amostras de linfonodos de pacientes com linfoma. A técnica de FISH foi realizada em material de parafina usando a sonda LSI FOXO1 (13q14) dual color, break apart rearrangement probe (Vysis, Abbott), seguindo as recomendaçóes do fabricante. $\mathrm{O}$ ponto de corte estabelecido foi de 6,2\%. Considerou-se positividade para a presença de alteração um resultado acima do ponto de corte. A caracterização de alteraçóes envolvendo o gene FOXO1 seguiu as regras do ISCN' .

\section{DISCUSSÃO}

O RMS é o sarcoma de partes moles mais comum que afeta crianças e adolescentes ${ }^{11}$. O RMSa é caracterizado pelas translocaçóes cromossômicas $\mathrm{t}(2 ; 13)$ (q35;q14) ou $\mathrm{t}(1 ; 13)(\mathrm{p} 36 ; \mathrm{q} 14)$, nas quais resulta na fusão de gene $\mathrm{P} A X 3$ FOXO1 ou PAX7-FOXO1 em $70 \%$ a $80 \%$ dos casos. As proteínas de fusão são consideradas fatores de transcrição, determinantes da tumorigênese $e^{3,5,12}$

A análise citogenético-molecular, isto é, a aplicação da FISH, tem sido utilizada como uma importante ferramenta diagnóstica para os casos de RMS de difícil diferenciação dos subtipos em nível histopatológico. A sonda mais frequentemente utilizada é a FOXO1 gene dual color break-apart que pode detectar ambas as translocaçóes envolvendo o gene $F O X O 1^{6,13}$. Atualmente, existe a proposta para a inclusão dessa alteração molecular como um dos fatores de prognóstico da doença ${ }^{14}$.

Neste relato de caso, empregou-se a metodologia de FISH utilizando-se a sonda FOXO1 gene dual color break-apart e foram observadas a presença de células com a translocação envolvendo o gene $F O X O 1$ e células apresentando um sinal extra desse gene. A paciente era portadora de RMSa, um subtipo de pior prognóstico e o tumor primário definido como localização parameníngea. Essa localização é considerada desfavorável e representa um grupo distinto, com controle da doença local pior do que os outros sítios, apresentando uma sobrevida global em dez anos de $66 \%^{8}$. A localização parameníngea e o subtipo alveolar sáo fatores prognósticos independentes para morte, seguindo uma recaída da doença ${ }^{15}$.

$\mathrm{O}$ achado da translocação envolvendo o gene FOXO1 com a associaçáo de uma cópia extra desse gene sugere uma evoluçáo molecular da doença com clones distintos. Os estudos que utilizaram o FISH para investigação da presença de rearranjos no gene FOXO1 em RMSa mostraram principalmente casos positivos para a translocação desse gene. Os sinais verde e vermelho separados indicam a translocação e o outro sinal de fusão 
na mesma célula; verde e vermelho justapostos indicam o alelo normal do gene FOXO1. Outra alteração bastante relatada é a amplificação, com a regiáo centromérica do gene apresentando (10-20) cópias extras do sinal verde, podendo ter uma frequência em até $50 \%$ dos casos de $\mathrm{RMSa}^{16,17}$. A amplificação do gene FOXO1 foi descrita pelo grupo cooperativo americano Children's Oncology Group (COG) e foi associada com um possível fator de bom prognóstico para o $\mathrm{RMS}^{8}$. Ao fazer uma revisão da literatura, verificou-se que este estudo corresponde ao primeiro caso de uma criança com RMSa apresentando a translocação do gene $F O X O 1$ e uma cópia extra desse gene em células distintas, correspondendo a clones separados.

\section{CONCLUSÃO}

A paciente relatada apresentou evoluçáo desfavorável, com progressão de doença e óbito. Entretanto, são necessários ainda novos estudos, a fim de compreender melhor o significado prognóstico da presença de clones com as alteraçóes citogenético-moleculares envolvendo a translocação e uma cópia extra do gene FOXO1.

\section{CONTRIBUIÇÕES}

Nicolas Cabral Cunha participou da execução da técnica FISH, no desenvolvimento do manuscrito e na revisão do artigo na sua parte final para envio do manuscrito para publicação. Arissa Ikeda Suzuki contribuiu com a pesquisa, interpretaçáo, desenho e análise crítica do conteúdo intelectual e na aprovação da versão enviada para publicação. Fernanda Ferreira da Silva Lima participou na interpretação dos resultados e descrição do caso e elaboração do manuscrito para envio para publicação. Priscila Valverde Fernandes contribuiu com a seleçáo e processamento do material histopatológico do caso analisado. Paulo Antônio Silvestre de Faria contribuiu com a identificação, revisóes e reanálise dos laudos anatomopatológicos, essencial para análise do caso, computação e análise dos resultados. Teresa de Souza Fernandez participou do desenho do estudo, foi responsável pela análise e interpretaçáo do resultado da FISH, no desenvolvimento do manuscrito, bem como na análise e revisáo do artigo na sua parte final para envio do manuscrito para publicação. Sima Esther Ferman participou do desenho do estudo, na elaboração do manuscrito, assim como na análise e revisão do artigo para envio para publicação.

\section{DECLARAÇÃO DE CONFLITO DE INTERESSES}

Nada a declarar.

\section{FONTES DE FINANCIAMENTO}

Não há.

\section{REFERÊNCIAS}

1. Siegel DA, King J, Tai E, Buchanan N, Ajani UA, Li J. Cancer incidence rates and trends among children and adolescents in the United States, 2001-2009. Pediatrics. 2014 Oct;134(4):e945-955.

2. Ward E, DeSantis C, Robbins A, Kohler B, Jemal A. Childhood and adolescent cancer statistics, 2014. Ca Cancer J Clin. 2014;64(2):83-103.

3. Gallego Melcón S, Sánchez de Toledo Codina J. Molecular biology of rhabdomyosarcoma. Clin Transl Oncol. 2007;9(7):415-419.

4. Missiaglia E, Williamson D, Chisholm J, Wirapati P, Pierron G, Petel F, et al. PAX3/FOXO1 fusion gene status is the key prognostic molecular marker in rhabdomyosarcoma and significantly improves current risk stratification. J Clin Oncol. 2012 May;30(14):1670-1677.

5. Parham DM, Barr FG. Classification of Rhabdomyosarcoma and its molecular basis. Adv Anat Pathol. 2013;20(6):387-397.

6. Davicioni E, Finckenstein FG, Shahbazian V, Buckley JD, Triche TJ, Anderson MJ. Identification of a PAX-FKHR gene expression signature that defines molecular classes and determines the prognosis of alveolar rhabdomyosarcomas. Cancer Res. 2006;66(14):6936-6946.

7. Williamson D, Missiaglia E, Reyniès A, Pierron G, Thuille B, Palenzuela G, et al. Fusion gene-negative alveolar rhabdomyosarcoma is clinically and molecularly indistinguishable from embryonal rhabdomyosarcoma. J Clin Oncol. 2010;28(13):2151-2158.

8. Duan F, Smith LM, Gustafson DM, Zhang C, Dunlevy MJ, Gastier-Foster JM, et al. Genomic and clinical analysis of fusion gene amplification in rhabdomyosarcoma: a report from the Children's Oncology Group. Genes, Chromosomes Cancer. 2012 Jul;51(7):662-674.

9. International Standing Committee on Human Cytogenomic Nomenclature. ISCN: an international system for human cytogenenomic nomenclature (2016). Basel: Karger; 2016.

10. Saxe DF, Persons DL, Wolff DJ, Theil KS. Validation of fluorescence in situ hybridization using an analytespecific reagent for detection of abnormalities involving the mixed lineage leukemia gene. Arch Pathol Lab Med. 2012;136(1):47-52.

11. Noone AM, Howlader N, Krapcho M, Miller D, Brest A, Yu M, et al. (editor). SEER Cancer Statistics Review, 1975-2015. [Internet]. Bethesda, MD: National Cancer Institute; April 2018. [cited 2018 Nov 13]. Available from: https://seer.cancer.gov/csr/1975_2015/ 
12. Shern JF, Chen L, Chmielecki J, Wei JS, Patidar R, Rosenberg M, et al. Comprehensive genomic analysis of rhabdomyosarcoma reveals a landscape of alterations affecting a common genetic axis in fusion-positive and fusion-negative tumors. Cancer Discov. 2014 Feb;4(2):216-231.

13. Mehra S, de la Roza G, Tull J, Shrimpton A, Valente A, Zhang S. Detection of FOXO1 (FKHR) gene break-apart by fluorescence in situ hybridization in formalin-fixed, paraffin-embedded alveolar rhabdomyosarcomas and its clinicopathologic correlation. Diagn Mol Pathol. 2008;17(1):14-20.

14. Gallego S, Zanetti I, Orbach D, Ranchère D, Shipley J, Zin A, et al. Fusion status in patients with lymph nodepositive (N1) alveolar rhabdomyosarcoma is a powerful predictor of prognosis: experience of the European Paediatric Soft Tissue Sarcoma Study Group (EpSSG). Cancer. 2018;124(15):3201-3209.

15. Chisholm JC, Marandet J, Rey A, Scopinaro M, de Toledo JS, Merks JHM, et al. Prognostic factors after relapse in nonmetastatic rhabdomyosarcoma: a nomogram to better define patients who can be salvaged with further therapy. J Clin Oncol. 2011;29(10):1319-1325.

16. Matsumura T, Yamaguchi T, Seki K, Shimoda T, Wada T, Yamashita T, et al. Advantage of FISH analysis using FKHR probes for an adjunct to diagnosis of rhabdomyosarcomas. Virchows Arch. 2008;452(3):251-258.

17. Papp G, Mihály D, Sápi Z. Unusual Signal Patterns of Break-apart FISH Probes Used in the Diagnosis of Soft Tissue Sarcomas. Pathol Oncol Res. 2017;23(4):863-871. 